BMJ Open

Sport \&

Exercise

Medicine

\title{
Inconsistent anticipatory postural adjustments (APAs) in rugby players: a source of injuries?
}

\author{
Danping Wang, ${ }^{1,2}$ Gael Mahe, ${ }^{3}$ Junying Fang, ${ }^{4}$ Julien Piscione,${ }^{5}$ Serge Couvet, ${ }^{6}$ \\ Didier Retiere, ${ }^{5}$ Sébastien Laporte, ${ }^{7}$ Pierre-Paul Vidal ${ }^{1,8}$
}

To cite: Wang D, Mahe G, Fang J, et al. Inconsistent anticipatory postural adjustments (APAs) in rugby players: a source of injuries? BMJ Open Sport \& Exercise Medicine 2018;4:e000303. doi:10.1136/ bmjsem-2017-000303

Accepted 12 March 2018
Check for updates

${ }^{1}$ School of Automation, Hangzhou Dianzi University, Zhejiang, China

2Plateforme d'étude de la Sensorimotricité, Université Paris Descartes, Paris, France ${ }^{3}$ UFR de mathématiques et informatique-LIPADE, Université Paris Descartes, Paris, France

${ }^{4}$ Faculté des sciences fondamentales et biomédicales, Université Paris Descartes, Paris, France

${ }^{5}$ Fédération Française de rugby, Marcoussis, France

${ }^{6}$ Thales Training and Simulation, Osny, France

${ }^{7}$ LBM/Institut de Biomécanique Humaine Georges Charpak, Arts et Metiers ParisTech, Paris, France

${ }^{8}$ CoGNition and ACtion Group (COGNAC-G), Université Paris Descartes-CNRS UMR-MD-SSA Paris, France

Correspondence to Dr Danping Wang; danping. wang@parisdescartes.fr

Dr Danping Wang; danping. wang@parisdescartes.fr

\section{ABSTRACT}

Background We are developing since 2010 with Thales and the Fédération Française de Rugby (FFR) M-Rex, a new kind of rugby scrum simulator. The study questioned whether it could improve safety and protect players from injury by using it as a tool for training/coaching the packs. Aim To explore the anticipatory postural adjustments (APAs) during the engagement of the ruck, because these predictive neck and back muscles contractions protect the spinal cord at the time of impacts, which is crucial to prevent injuries.

Methods We quantified the kinematics and the EMG activities in high-level front row players during their initial engagement, when scrummaging with M-Rex. All studies were performed with one player interacting with the robot, at first, and then with the three players acting together. Results For most of the tested high-level players, the APA latencies were highly variable from trial to trial even though the engagement resulted in similar impacts. At time, the onset of the electromyography activity in the neck and back muscles showed latencies inferior to $50 \mathrm{~ms}$ or even close to zero prior to the impact, which rendered muscle contractions inefficient as APAs. We were also unable to identify clear muscular synergies underlying the APAs because of their great variability on a trial-to-trial basis. Finally, the APAs were not related to the amplitude of the ensuing impact and were asymmetric in most trials. All these characteristics held true, whether the player was playing alone or with two other frontline players.

Conclusion Our result suggest that APAs should be systematically tested in high-level rugby players as well as in any high-level sport men at risk of neck and back injuries. Because APAs can be efficiently trained, our study paves the way to design individual position-specific injury prevention programme.

\section{INTRODUCTION}

The scrum is a full contact, collective and complex event that occurs during a relatively small period of game-time in the rugby union. It involves an engagement followed by an intense sustained push. The scrum is considered as a major cause of injury in rugby unions. The proportion percentage of injuries related with scrum is $<8 \%$ of all rugby union injuries. ${ }^{12}$ However, roughly $40 \%$ of

\section{What are the new findings?}

- Anticipatory postural adjustments (APAs) play a crucial role in motor control. For instance, in rugby, during the engagement of the ruck, predictive neck and back muscles contractions protect the spina cord at the time of impacts, which is crucial to prevent injuries.

- In this study, we used a rugby scrum simulator to investigate the characteristics of the APAs in high-level rugby players.

- Surprisingly, they were quite erratic and sometimes delayed to such a point that they often could not be useful to protect the neck and the back during the impacts.

- Our result suggest that APAs should be systematically tested in high-level rugby players and in any high-level sport men at risk of neck and back injuries.

- Then they should be trained if necessary with specific prevention programme.

all serious cervical spine injuries in rugby are related to scrumming. ${ }^{34}$ An American survey spanning almost three decades (19701996) shows that $58 \%$ of the 62 documented injured players damaged their cervical spines during the scrum. Sixty-four per cent of the injuries occurred when the opposing packs came together (engagement), and 36\% when the scrum collapsed. ${ }^{5}$ Thirty-seven cases of catastrophic cervical spine injuries in French rugby were reported from 1996 to 2006 and the scrum was identified as a major cause for injury, accounting for $51 \%$ of the cases. ${ }^{6}$ The biomechanical constraints at play during the scrum may explain why the front row players are more exposed to chronic and catastrophic spinal injuries. ${ }^{25-11}$ The hooker is particularly vulnerable as he accounts to $78 \%$ and $37.8 \%$ of the cervical injuries surveyed in the studies by Wetzler $e t a l^{5}$ and Bohu et $a l^{6}{ }^{6}$ respectively. For the interested reader, more accurate details of occurrences of cervical injuries in rugby can be found in the reviews 
by Quarrie et al, Kaplan et al, Kuster et al, Trewartha et al and McIntosh and McCrory. ${ }^{312-15}$

As cervical lesions prevail among rugby players, it was recommended to design individual positionspecific injury prevention programme taking into account the player's previous injuries. ${ }^{21216}$ Another approach to prevent accident was to gain a deeper understanding of the game, and of the scrummaging technique, in particular, which was first studied by Milburn. ${ }^{17}$ It was found that the anthropometric characteristics and physical performances of forwards differed significantly among positional categories to best meet the demands imposed on them by their position. ${ }^{18} 19$ Furthermore, the packs that produced the largest scrummaging forces were characterised by a greater pack force to sum of individual force ratio than the packs producing lower forces. ${ }^{20}$ Preatoni $e t \quad a l^{21}$ investigated machine scrummaging at different playing levels in rugby union and analysed kinetic factors that might influence performance and injury risk. They found that the magnitude of the measured forces is in the range of values that studies on cadaveric specimens have indicated as potentially hazardous for spine injuries. Also, players scrummaging on synthetic turf demonstrated less angular velocity in the lower thoracic spine, which suggested that the support surface is of importance to prevent injuries. ${ }^{10}$

Finally, the modification of the engagement technique turned out to be an important landmark for injury prevention by altering the load acting on players during the scrum. Preatoni et $a l^{2223}$ and Cazzola et $a l^{24-26}$ have shown that, irrespective of the playing level, reducing the dynamics of the initial engagement through a fold-in procedure decreased the peak compression force, the peak downward force and the engagement speed in excess of $30 \%$. Also, de-emphasising the initial impact against the scrum decreased the mechanical stresses acting on forward players and benefit players' welfare by reducing the hazard factors that may induce chronic degeneration of the spine. Altogether then, as pointed out by Quarrie and Wilson, ${ }^{20}$ there is a need for a scrum pack to develop technique and coordination as a unit to maximise scrummaging force and prevent accident. In order to contribute to that goal, we have investigated the APAs in rugby players in collaboration with the Fédération Française de Rugby (FFR).

APAs are commonly described as unconscious muscular activities aimed to counterbalance the perturbation caused by the primary movement, so as to ensure the whole-body balance, as well as contributing to initiate the displacement of the body centre of mass when starting gait or whole-body reaching movements. ${ }^{27-31}$ Consequently, APAs are generated prior to a predictable perturbation irrespective of its external and internal origin. ${ }^{32}$ Moreover, when the timing, the kinetic energy of the perturbations can be forecast based on visual and/ or proprioceptive cues and/or motor efferent copies, APAs can be calibrated to minimise the forthcoming body perturbation. ${ }^{33-37}$ Hence, despite the fact that
APAs are acquired based on previous experiences and learning, they exhibit short-term adaptation in response to immediate environmental changes, for instance, when stability changes. ${ }^{38} 39$ Being these characteristics, APAs likely play a central role in rugby being the prevalence of postural perturbations and collisions and if they are not well adapted, the players could be at risk of injuries, particularly at back and neck levels.

Neck muscles display two patterns of APAs, which are task-specific. A reciprocal pattern prevails in anticipation of perturbation acting directly on the head. A simultaneous activation pattern is used when the direction of head perturbation is uncertain. ${ }^{40-42}$ As in lower limbs and neck, direction-specific patterns of anticipatory trunk muscle activity can be recorded at the onset of when pointing. ${ }^{43}{ }^{44}$ Finally, APAs are not of reflexive origin: the primary motor cortex and supplementary motor area contribute to their generation both in term of timing and amplitude and the posterior cerebellum is involved in the coupling between the APAs and motor execution. ${ }^{45-47}$ From there, the ventral corticospinal tract, ${ }^{48}$ the reticulospinal tract and associated pontomedullary reticular formation participate in the descending control of the proximal and distal musculature and the encoding of APAs. ${ }^{49} 50$

In order to study the APAs in rugby players, we used M-Rex, a robotic scrum simulator we designed in 2010 with Thales and the FFR, which turned out since then to be a valuable tool for training/coaching the packs of the national. We quantified the kinematics and the electromyography (EMG) activities of high-level front row players during their initial engagement and during the ensuing sustained push, when scrummaging with M-Rex. All studies were performed with only one player interacting with the robot, at first, and then with the three players acting together.

\section{METHODS}

\section{Participants and the M-Rex simulator}

All data collections were recorded at the FFR's Centre national du rugby at Linas-Marcoussis (Essonne) during the regular training programme of the French national team. Nine front row players from the 'Pôles Espoirs Masculin' (means: height $=1.75 \pm 0.05 \mathrm{~m}$, mass $=85.6 \pm 10$ $\mathrm{kg}$, age $=20 \pm 3$ years) participated in the data record. All participants provided written informed consent. We tested three groups of three players, that is, nine players, who used to play together as frontlines at the national level.

The M-Rex scrum simulator, illustrated in figure 1 , is an intelligent robot equipped with force sensors. It uses a motion system routinely operated for tank simulator at Thales. To reproduce the interplay of a scrum situation, the simulator treats the scrum formation as an object in space. Thanks to its hexapod system, M-Rex reconstructs the scrum environment by moving the beam left and right, backwards and forwards, up and down, with a threeaxis rotation. M-Rex applies the man-in-the-loop concept 


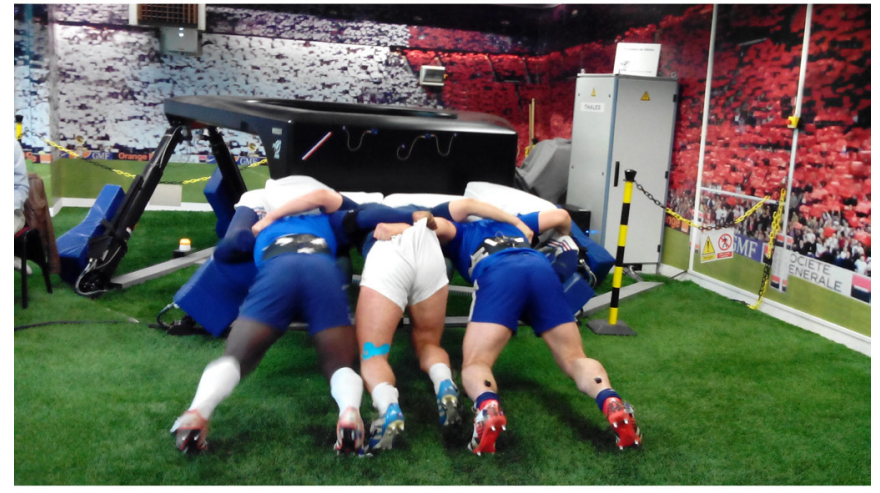

Figure 1 Three front row players scrummaging on the M-Rex simulator.

of interactive simulation: players act on the simulator in response to the sensations they feel as the machine moves. In a continuous loop, the simulator responds to player inputs by moving and pushing back. The latest version of M-Rex can translate over several metres frontwards and backwards but it was not used in the present study.

\section{Experimental protocol}

We tested three groups of three players, who used to play together as frontlines at the national level. They were tested with the crouch-touch-set protocol, which was used before the new engagement rules. The simulator was passive and then it responded to the player(s) push by an opposite and continuous force in order to simulate the reaction of the scrum's opposite players. The perturbation was applied randomly at $0.5,1.5$ and $2.5 \mathrm{~s}$ after the engagement. It displayed a rectangular profile of $2 \mathrm{KN}$ for $10 \mathrm{~s}$ and was oriented at random either frontwards or upwards or sideways. The force sensors integrated in the beam (figure 1) simultaneously measured the force exerted by each of the three players. These signals were sampled at $200 \mathrm{~Hz}$. The simulator triggered the Codamotion to start recordings.

The Codamotion system (Coda CX1 Scanner Units) is an active three-dimensional motion tracking system (Charnwood Dynamics, Rothley, Leicester). Fifteen markers were placed on each player's body. For the spine and inferior limb markers, we used clusters: Codamotion clusters are lightweight rigid body, which carries three markers that gives $6 \mathrm{df}$ information when attached to the body. They are easier to apply than individual markers:

- One cluster was fixed on the spine at L5 level (ie, 3 markers);

- Two clusters were fixed on each limb (ie, $2 \times 3$ markers);

- Three markers were fixed on each rugby shoe at the fifth metatarsal level and at the lateral and back sides of the calcaneus (ie, $2 \times 3$ markers).

These markers were detected by three Coda CX1 units (scanners) placed on tripods in the training facility to cover the scrumming range. The system's 'x-axis' was defined as the direction of the players engagement and the axis origin (zero point) corresponded to the initial position of the hooker player (middle position). Each recording lasted $20 \mathrm{~s}$. The rate frequency of the recordings was $100 \mathrm{~Hz}$. The signals were processed with Matlab routines.

The EMG activities were recorded via the Trigno Wireless EMG System. Each EMG sensor has a built-in triaxial accelerometer, a transmission range of $40 \mathrm{~m}$ and a rechargeable battery lasting up to 8 hours.

Surface EMG from 10 or 12 muscles in the legs and trunk were collected at $1000 \mathrm{~Hz}$, and synchronised with body-segment kinematics collected at $100 \mathrm{~Hz}$. EMGs were recorded from the following muscles on both sides of the body: tibialis anterior; rectus femoris; semi-tendinosus; medial gastrocnemius; ES, erector spinae muscles at L2 level; sterno-cleido-mastoidus and TRAP, trapezius at C2 level.

\section{Data processing}

We studied the APAs of the three groups of front row players during individual and collective engagement. During the engagement, the onset of the EMG activity was defined as the time it exceeded twice the $\operatorname{SD}(2 \sigma)$ of the EMG activity at rest, recorded during $600 \mathrm{~ms}$ before the engagement. Similarly, we defined the onset of the engagement as the time the force signal exceeded $2 \sigma$ of the noise level recorded at rest. Raw EMG signals were high-pass filtered at $10 \mathrm{~Hz}$, half-wave rectified and low-pass filtered at $250 \mathrm{~Hz}$, using a sixth Butterworth filter. The APA onset was defined as the time difference in milliseconds between the onset of the EMG activity and the onset of the engagement defined on the force recordings (figure 2 ).

\section{RESULTS}

\section{Engagement force}

As quoted in the 'Methods' section, we tested three groups of three players, who used to play together as frontlines at the national level. Figure 3 displays two Fx force recordings averaged over 14 trials of three players of group 1 . The records of the first row illustrates Fx when the left pillar, the hooker and the right pillar played alone. The records of the second row illustrates Fx when they played together. The first three peaks of force were of the same duration when the players played alone. The peaks of force were of the variable duration and of the different form when they played together. Their amplitudes were more variable than their durations. Also the first peak of force tend to be larger when the players played together.

To document these differences, we quantified the amplitude and duration of the first peak of force in group 1 for the $\mathrm{Fx}, \mathrm{Fy}, \mathrm{Fz}$ recordings when the players were scrummaging alone and together. Table 1 summarises the mean and the SD of the durations and amplitudes of the first peak of force, respectively, as well as the number of trials used for their computation. Note that we discarded trials where the force signal did not exhibit 


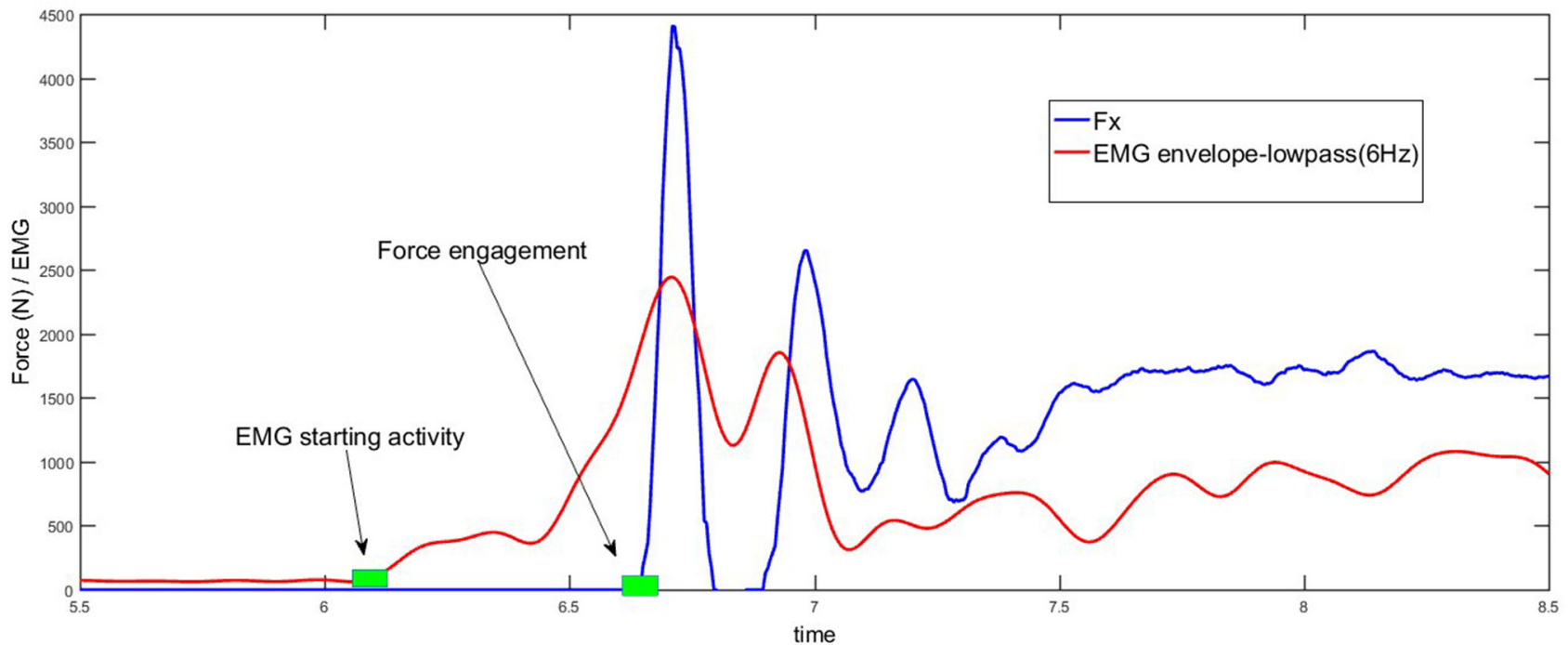

Figure 2 The relationship between the electromyography (EMG) (red) and the force Fx (blue) at engagement moment. Anticipatory postural adjustment is the difference time between the EMG starting activity and the force engagement.

a peak $>1000 \mathrm{n}$, considering that they were not representative of an engagement.

\section{The APAs}

APAs are of major interest for front row players because they play a major role in the protection of the neck and spine before the impact, during the engagement phase and later during the scrum. In this paper, we chose to define APA with respect to EMGs, that is, APA were measured during the time interval between the EMG onset in various muscles and the impact onset during the engagement.

Figure 4 illustrates the force (dot), the amplitude (diamond) and the latencies (square) of the APAs recorded in the TRAP and ES muscles during eleven consecutive trials in the three front row players of group
1, for which we undertake a detailed analysis of the APA. The two upper row of the figure displays the performance of the left pillar, the two middle row those of the hooker and the last two rows the ones of the right pillar. For a given player we displayed side by side the result recorded for the EMG of the left and right TRAP and ES muscles. For each player, the upper row displays the data collected when the player played alone and the inferior one, when he played with the frontline players. The scale in ordinate corresponds a- to the latencies from 0 to $1 \mathrm{~s}$, b- to the force from 0 to 1 time $10^{3} \mathrm{~N}$, c- to the EMG amplitude normalised value from 0 to 1 . The amplitude was normalised with respect to the maximum force exerted by each player. Several characteristics of the APAs can be readily observed. The APAs latencies and amplitude and the force at the impact were highly variable on a
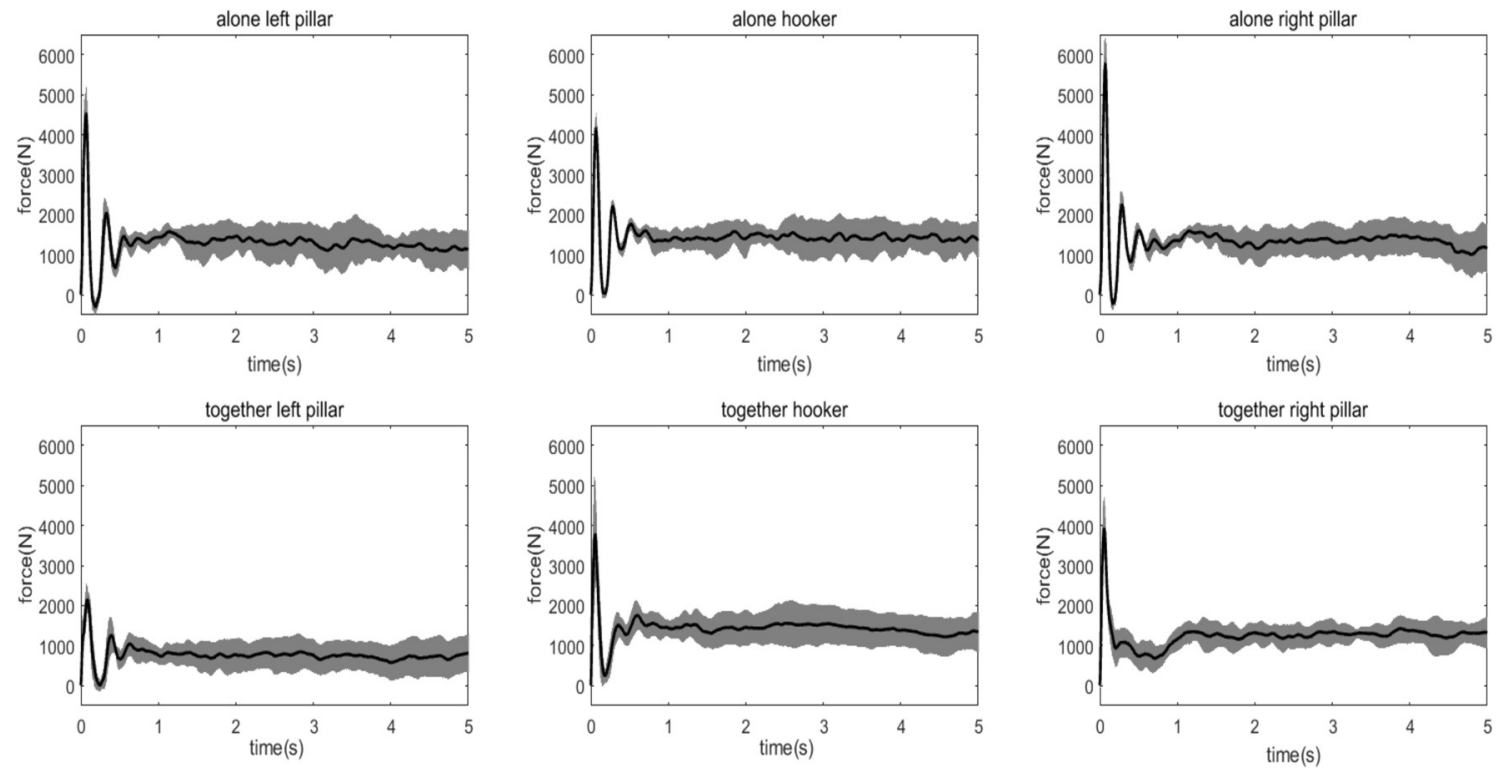

Figure 3 The two Fx force recordings averaged over 14 trials of one player of group 1. The top row illustrates Fx when three frontline players played alone and the bottom row illustrates Fx when they played together. 
Table 1 Mean and SD of the duration of the first peak (ms) and maximum, mean and SD of the force (N) during the transient phase in group 1

\begin{tabular}{|c|c|c|c|c|}
\hline & & Left pillar & Hooker & Right pillar \\
\hline \multicolumn{5}{|c|}{ Duration and SD of the first peak (ms) } \\
\hline \multicolumn{2}{|l|}{ Alone } & $257 \pm 15, n=14$ & $214 \pm 70, n=13$ & $215 \pm 11, n=13$ \\
\hline \multicolumn{2}{|l|}{ Together } & $296 \pm 67, n=11$ & $253 \pm 48, n=11$ & $337 \pm 102, n=5$ \\
\hline \multicolumn{5}{|c|}{ Maximum amplitude, mean amplitude and SD of the maximum of the first peak (N) } \\
\hline \multirow[t]{3}{*}{ Alone } & Fx & $5661,4296 \pm 650$ & $4803,3807 \pm 722$ & $7141,5208 \pm 1193$ \\
\hline & Fy & $885,520 \pm 164$ & $785,446 \pm 177$ & $823,364 \pm 321$ \\
\hline & $\mathrm{Fz}$ & $909,720 \pm 142$ & $1205,858 \pm 136$ & $1080,825 \pm 128$ \\
\hline \multirow[t]{3}{*}{ Together } & Fx & $3035,792 \pm 418$ & $5759,1357 \pm 505$ & $5222,1275 \pm 419$ \\
\hline & Fy & $405,140 \pm 173$ & $705,146 \pm 201$ & $914,225 \pm 194$ \\
\hline & $\mathrm{Fz}$ & $950,223 \pm 283$ & $1277,447 \pm 275$ & $905,231 \pm 289$ \\
\hline
\end{tabular}

trial-to-trial basis for the same player and from one player to the other. This variability explained that no definite pattern of muscle contractions emerged in the neck and back muscles during the APAs. Also, the APAs' latencies of the players were often inferior to $50 \mathrm{~ms}$ and sometime became close to $0 \mathrm{~ms}$, which clearly put them at risk. This is illustrated in figure 4 by the intermittent poor performance of the left pillar. Also, and curiously enough, the right pillar performed correctly when playing alone and poorly when playing together with the frontline players.

We questioned also whether the latencies of the APA were related to the amplitude of the first peak of force during the engagement when the players were tested alone or together with the two other players of the front line. Figure 5 illustrates there was no correlation between these two variables whether the player was tested alone or together.

Finally, we tested the symmetry of the APA latencies and amplitude, with the underlying hypothesis that the more symmetric these values are, the better, because each player has to exert the engagement in the straightahead direction. The results are illustrated in figure 6 . The symmetry is expressed by the difference between the latencies and amplitude observed in the right and left muscles (for TRAP and ES muscles) during 14 consecutive trials. A value of 0 denoted a perfectly symmetric discharge both in terms of timing and amplitude. As a rule, the APAs were asymmetric and it varied from trial to trial and muscle to muscle without systematic pattern, whether the players played alone or together.

\section{DISCUSSION}

The force signals we recorded during the engagement always exhibited two phases. First, we observed a transient phase just after the impact, composed of two or three peaks, similar to a damped sinusoid. Then, the transient phase was followed by a sustained phase, with reduced oscillations. As for the transient phase, our study confirms the results of Preatoni et $a l^{21}$ the first peak was very brief but could reach very high level (table 1 ), in the range of values that studies on cadaveric specimens have indicated as potentially hazardous for spine injuries. These findings call for the following comments. Considering the magnitude of the forces at play, the presence of a negative peak force and the capricious nature of the APAs, we proposed with other scholars to modify the rule governing the engagement, which came rapidly into effect. The opposing front rows of the scrum-the hooker and the props-now enter a 'prebind' before engaging, which was proposed to reduce the speed at which the two sides come together, limiting the number of potentially dangerous scrum collapses. Subsequent studies by Preatoni et $a l^{2223}$ and Cazzola et $a l^{24-26}$ demonstrated that these changes of rules were indeed efficiently reducing the dynamics of the engagement and the mechanical stresses acting on forward players. However, it may not influence the spinal kinematics of the hooker during live scrummaging. ${ }^{10}$

We hypothesised that a voluntary impact at the engagement during the ruck or during any phase of the game was preceded by an APA to damp the perturbation of the posture caused by the ongoing impact. ${ }^{31}$ As expected, we showed that it was indeed the case: the predictive neck and back muscles contractions protected the spinal cord at the time of the impact. However, it came as a surprise that for most of the tested high-level players the APA latencies were highly variable from trial to trial even though the engagement resulted in similar impacts. Also, at time, the onset of the EMG activity in the neck and back muscles showed latencies inferior to $50 \mathrm{~ms}$ or even close to zero prior to the impact. It rendered muscle contractions inefficient as APAs, being the $50 \mathrm{~ms}$ delay imposed by the electromechanical coupling. We were also unable to identify clear muscular synergies underlying the APAs because of their great variability on a trial-to-trial basis. Finally, the APAs were not related to the amplitude of the ensuing impact and were asymmetric in most trials. All these characteristics held true, whether the player was playing alone or with two other frontline players. Now, being the fact that APAs are essential to the engagement 

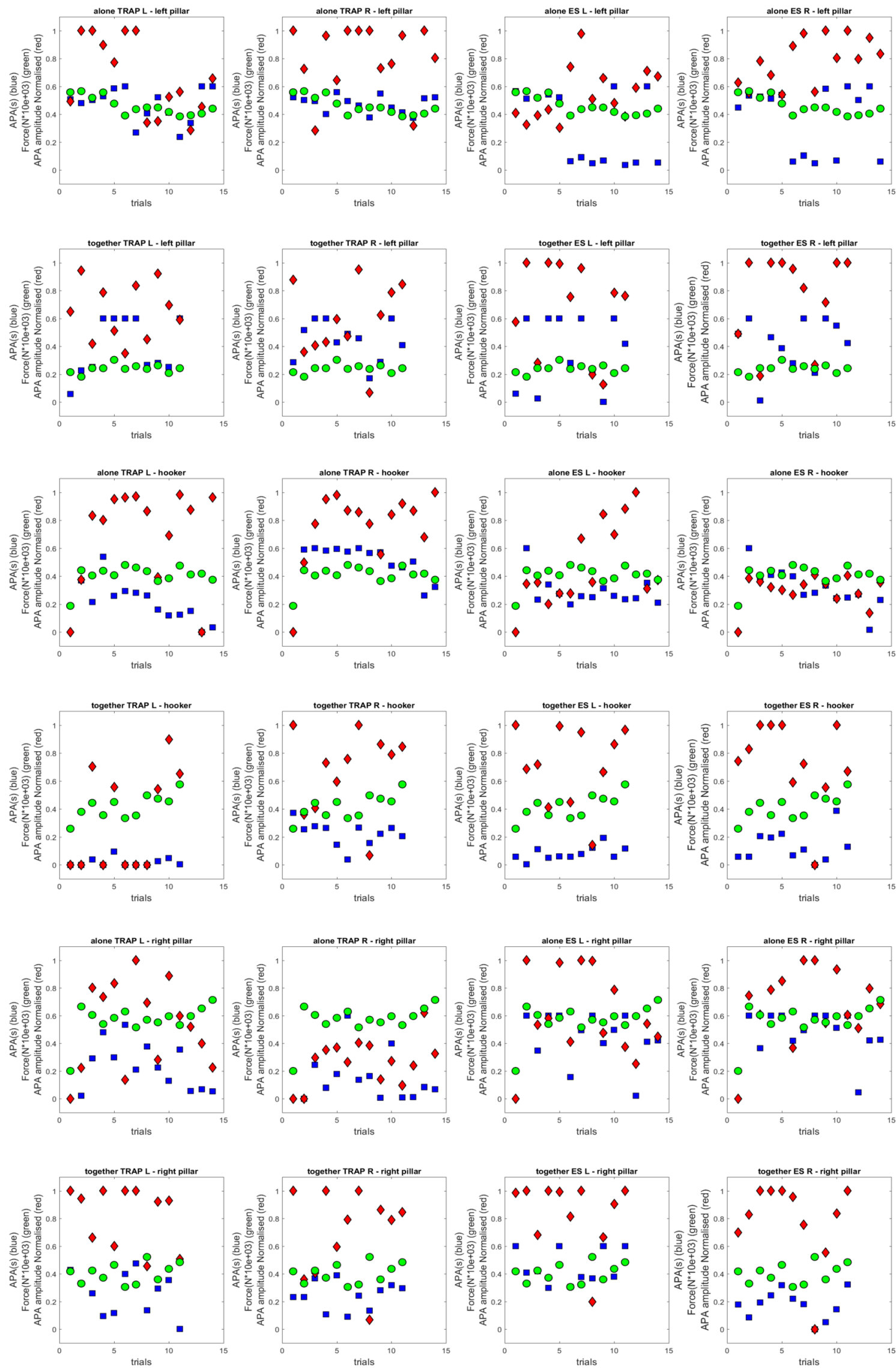

Figure 4 The latency of the anticipatory postural adjustments (APAs) (blue square), the force (green dot) and the amplitude (red diamond) recorded in the trapezius at C2 level (TRAP) and erector spinae (ES) muscles during 11 consecutive trials in the three front row players of group. 




Figure 5 The figure illustrates that there is no correlation between anticipatory postural adjustment (APA) latency and APA amplitude.

of the scrum, and during any impact during the course of the game it may explain why tackles are game events responsible for the highest number of injuries. ${ }^{1}$ Therefore, the question arises why, despite the fact that APAs can be timely and adapted (see the 'Introduction' section), they were irregular and erratic in that study.

To our knowledge, there are few studies where the regularity of APAs were found to be modified. Lin et al $l^{51}$ found an increased variability of APAs in patients with Parkinson's disease during gait initiation, which may affect their posture-locomotion coupling and lead to start hesitation and even falls. Also, the variability of APA onset times was decreased in people with chronic low back pain at acute and chronic stage ${ }^{5253}$ and this was unrelated with the participants' reported levels of pain or disability. Hence, one can speculate that the variability of APAs may not be striking compared with the other muscular synergies underlying postural control in healthy individuals. Rather, as pointed by Moseley et $a{ }^{52},{ }^{52}$ APAs variability is probably optimal for adaptive motor control, as it is the case for other motor synergies. Hence, we do not believe that the large variability we observed in rugby players can be considered as a normal feature of motor control during daily activities.

One explanation to the variability and asymmetry of the APAs in the present study could be related to the asymmetric stance adopted by the two pillars and the hooker during the engagement. Whether they played alone or together, their dominant leg was placed in front of other one at the onset of the engagement and remained so. The legs placement was less asymmetric in the hooker when playing with the pillars but it was still present. This asymmetric posture maybe an important point because when Lee and Aruin ${ }^{545}$ investigated the effects of symmetric stance and pushing movements on APAs, asymmetric stance was associated with larger muscle activity of the backward leg and asymmetric pushing movement with larger trunk muscle activity on the contralateral side. Combining in various ways asymmetric stance and pushing movements resulted in the increase or decrease of the thigh muscle activity and mediolateral centre of pressure displacement depending on whether both asymmetries were induced on the same side of the body or on opposite sides. The same group ${ }^{36}$ investigated APAs during lateral perturbations and showed again that they were modulated depending on the type of stances and the side of the postural perturbation. Prior studies of postural control associated with either symmetric upper limb movement while standing asymmetrically ${ }^{56}$ or unilateral or bilateral arm movement while standing symmetrically $^{57-59}$ support the conclusion that postural asymmetries affect APAs. Altogether then, the asymmetric posture adopted during the ruck could partly explain the asymmetric APAs in the neck and back musculature we observed. The considerable interindividual and intraindividual variability of the APAs could also be linked to interindividual differences in the posture adopted by the players during the engagement phase and its variation from trial to trial in the same player.

Another source of asymmetry and irregularity of the APAs could be unnoticed chronic pain in some players. Larivière $e t a l^{60}$ showed that combining attention interference with non-specific chronic low back pain delayed APA in trunk muscles during postural tasks. That is, players with any pain, performing a complicated physical task such as a ruck, which requires a lot of attention, could be at greater risk of injury. Also, pain may not even be a perquisite: the association of an unnatural posture with a voluntary head-on collision may constitute a sufficiently complex double task to explain the poor quality of APAs during that exercise. On argument in favour of that hypothesis is the fact that during the sustained phase of the ruck, every changes of placement of one foot of a player was consistently accompanied by a dramatic decrease of the force he could exert (to be published).

If inefficient APAs are most probably linked to balance impairment and poor motor skills, their improvement in rugby players should ameliorate their motor performance as it was shown by Santos and Aruin ${ }^{37}$ that improving APAs improved the quality of motor control. A first suggestion to reach that goal would be to test systematically and regularly the players to detect the problem. As quoted above, a particular attention should be payed to players with chronic pain. Also, it appears that women may be more at risk. ${ }^{61}$ Once detected, abnormalities of the APAs shoud amended and several studies suggest it is indeed feasible. Adequate exercise programme improved APAs in obese people. ${ }^{62}$ Similarly, according to the review of Calatayud et $a l^{63}$ appropriate exercise prescription should increase the quality of static and dynamic balance and decrease injury recurrence. In particular, dynamic activities would be beneficial by improving APAs, considered as a key factor in the injury mechanism. Exercise was also suggested to be beneficial in young participant exhibiting fear of falling, 


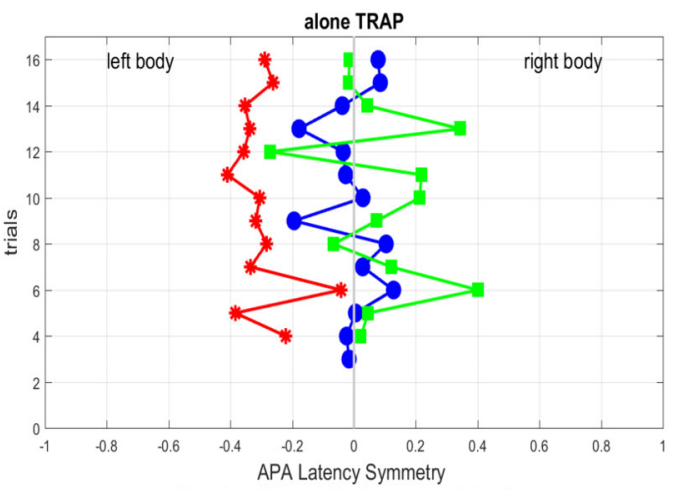

blue: left pillar, red: hooker, green: right pillar

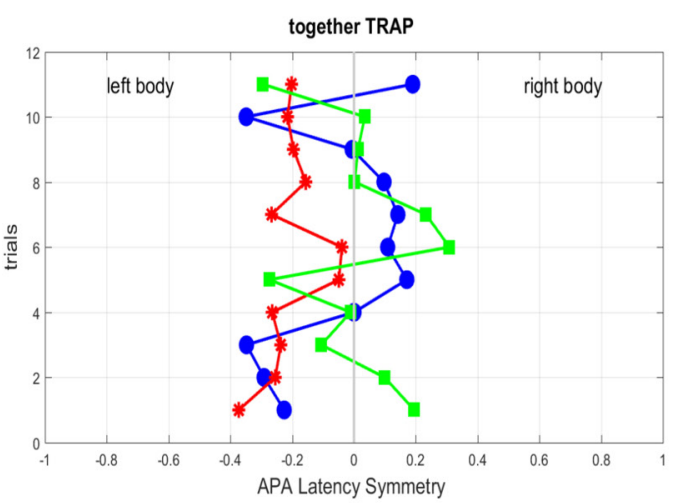

blue: left pillar, red: hooker, green: right pillar
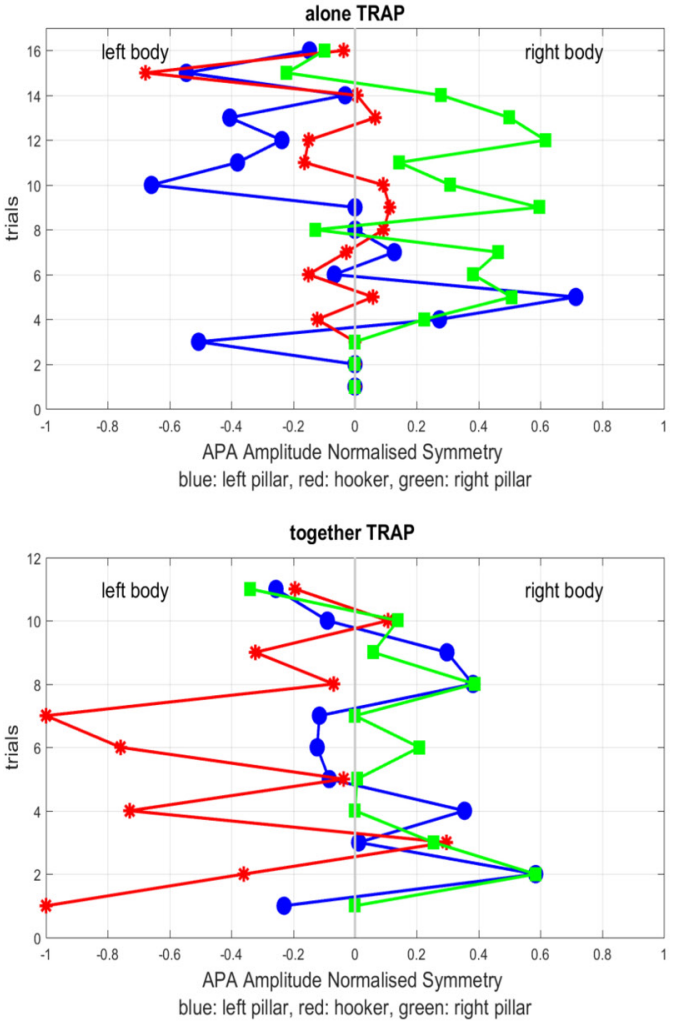

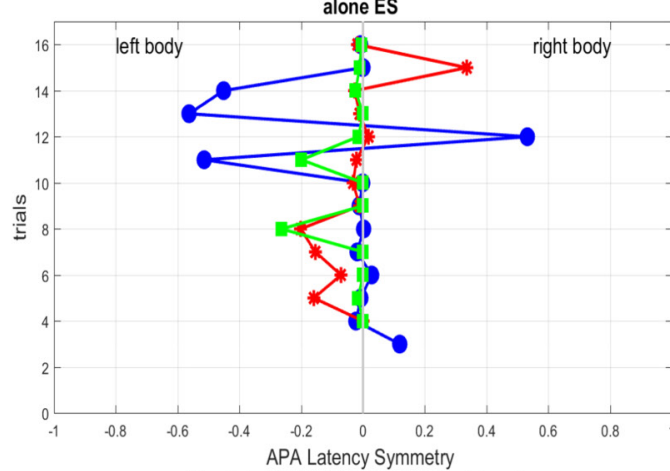

blue: left pillar, red: hooker, green: right pillar

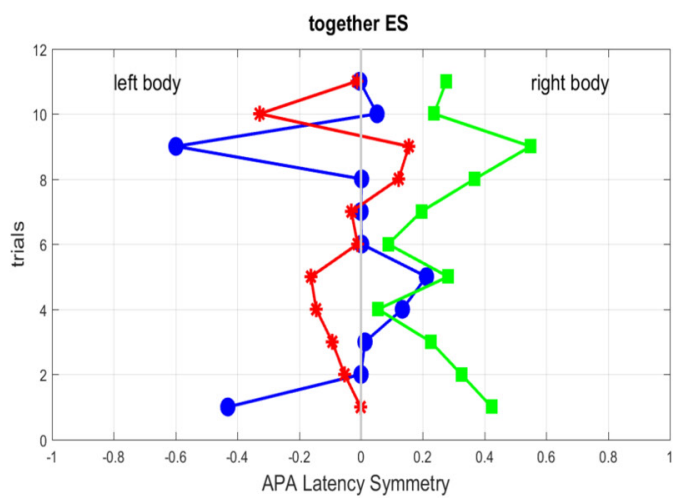

blue: left pillar, red: hooker, green: right pillar

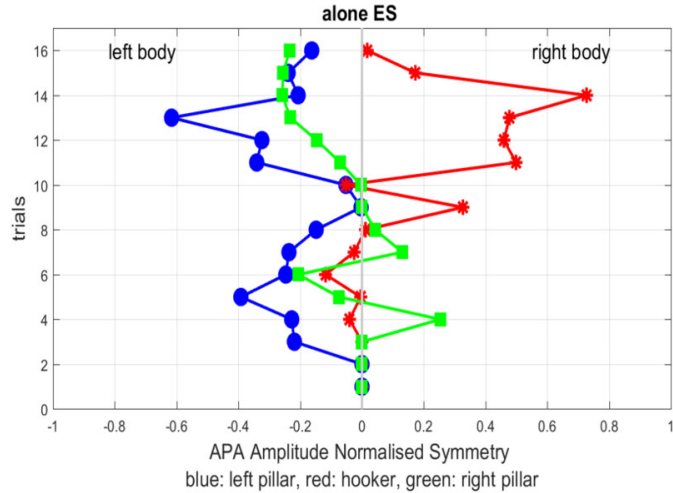

together ES

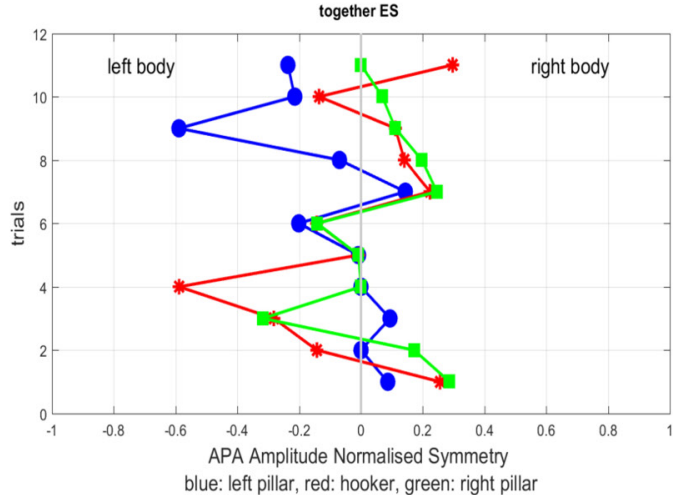

Figure 6 The symmetry of the anticipatory postural adjustments (APAs) is expressed by the difference between the latencies and amplitude observed in the right and left muscle for the right and left trapezius at C2 level (TRAP) and erector spinae (ES) muscles during 14 consecutive trials. Blue circles, red stars and green squares correspond to latencies (A) or amplitude (B) recorded in the left pillar, the hooker and the right pillar, respectively. 
which provoke a decrease of APAs' amplitude ${ }^{64}$ and in elderly exhibiting inefficient APAs at the precrossing phase of obstacle negotiation. ${ }^{65}$ When considering sport practice, planning appears to be important. Mornieux $e t a l^{66}$ studied cutting manoeuvres in football game under time pressure. They found that increasing lateral trunk flexion was the most effective strategy to cope with the problem, but it was increasing the risk of knee injury. The authors suggest that training programme improving APAs would help to solve the problem. In summary, there is a consensus that at every age and in various circumstances including sport, APA can be deficient and that they should be trained.

In that context, it is interesting that recent studies show that APAs can indeed be improved. In two studies in patients with low back pain, sensorimotor training was effective in improving delayed and decreased APAs, which alleviated pain, and improved muscle strength. ${ }^{67} 68$ Also Kanekar and Aruin ${ }^{69}$ recently designed a specific programme to improve APAs. They exposed the subjects to predictable external perturbations before and after a single training session consisting of catches of a medicine ball thrown at the shoulder level. The effect of a single training session resulted in significantly earlier muscle onsets and larger anticipatory centre of pressure displacements.

Contributors DW (research engineer): Assistance of coordination, recordings at the FFR, signal processing and drafted the Methods and Results sections. GM (associate professor): supervised signal processing and processed part of the signals. JF (Master's student): helped to process the signals by writing software. JP (head of the scientific department of the FFR): coordinator of the recording sessions at the FFR centre, operator of the robot and participated in the interpretation of the data. SC (engineer): maker of the robot and technical supervisor to the recordings session. DR (technical director of the FFR): in charge of the scientific programme at the FFR. SL (professor): participation in the data interpretation. P-PV: coordination of the study, head of the group and drafted the Introduction and Discussion sections.

Funding This study was funded by Fédération Française de Rugby.

Competing interests None declared.

Patient consent Not required.

Ethics approval This study was approved by the FFR and conducted in accordance with the Declaration of Helsinki.

Provenance and peer review Not commissioned; externally peer reviewed.

Open Access This is an Open Access article distributed in accordance with the Creative Commons Attribution Non Commercial (CC BY-NC 4.0) license, which permits others to distribute, remix, adapt, build upon this work non-commercially, and license their derivative works on different terms, provided the original work is properly cited and the use is non-commercial. See: http://creativecommons.org/ licenses/by-nc/4.0/

(c) Article author(s) (or their employer(s) unless otherwise stated in the text of the article) 2018. All rights reserved. No commercial use is permitted unless otherwise expressly granted.

\section{REFERENCES}

1. Fuller CW, Laborde F, Leather RJ, et al. International Rugby board Rugby world cup 2007 injury surveillance study. Br J Sports Med 2008;42:452-9.

2. Brooks JH, Fuller CW, Kemp SP, et al. Epidemiology of injuries in English professional rugby union: part 1 match injuries. $\mathrm{Br} J$ Sports Med 2005;39:757-66.

3. Quarrie KL, Cantu RC, Chalmers DJ. Rugby union injuries to the cervical spine and spinal cord. Sports Med 2002;32:633-53.
4. Fuller CW, Brooks JH, Cancea RJ, et al. Contact events in rugby union and their propensity to cause injury. $\mathrm{Br} J$ Sports Med 2007;41:862-7.

5. Wetzler MJ, Akpata T, Laughlin W, et al. Occurrence of cervical spine injuries during the rugby scrum. Am J Sports Med 1998;26:177-80.

6. Bohu Y, Julia M, Bagate C, et al. Declining incidence of catastrophic cervical spine injuries in French rugby: 1996-2006. Am J Sports Med 2009;37:319-23.

7. Silver JR. Injuries of the spine sustained during rugby. $\mathrm{Br} J$ Sports Med 1992;26:253-8.

8. Brooks JH, Fuller CW, Kemp SP, et al. A prospective study of injuries and training amongst the England 2003 Rugby World Cup squad. Br J Sports Med 2005;39:288-93.

9. Brown JC, Lambert MI, Verhagen E, et al. The incidence of rugby-related catastrophic injuries (including cardiac events) in South Africa from 2008 to 2011: a cohort study. BMJ Open 2013;3:e002475.

10. Swaminathan R, Williams JM, Jones MD, et al. Does the new rugby union scrum sequence positively influence the hooker's in situ spinal kinematics? BMJ Open Sport Exerc Med 2016;2:e000064

11. Cross $M$, Kemp S, Smith A, et al. Professional Rugby union players have a $60 \%$ greater risk of time loss injury after concussion: a 2 -season prospective study of clinical outcomes. Br J Sports Med 2016;50:926-31.

12. Kaplan KM, Goodwillie A, Strauss EJ, et al. Rugby injuries: a review of concepts and current literature. Bull NYU Hosp Jt Dis 2008;66:86-93.

13. Kuster D, Gibson A, Abboud R, et al. Mechanisms of cervical spine injury in rugby union: a systematic review of the literature. $\mathrm{Br} J$ Sports Med 2012;46:550-4.

14. Trewartha G, Preatoni E, England ME, et al. Injury and biomechanical perspectives on the rugby scrum: a review of the literature. $\mathrm{Br} \mathrm{J}$ Sports Med 2015;49:425-33.

15. Mclntosh AS, McCrory P. Preventing head and neck injury. $\mathrm{Br} J$ Sports Med 2005;39:314-8.

16. Quarrie KL, Gianotti SM, Hopkins WG, et al. Effect of nationwide injury prevention programme on serious spinal injuries in New Zealand rugby union: ecological study. BMJ 2007;334:1150-3.

17. Milburn PD. The kinetics of rugby union scrummaging. J Sports Sci 1990;8:47-60.

18. Quarrie KL, Handcock P, Toomey MJ, et al. The New Zealand rugby injury and performance project. IV. Anthropometric and physical performance comparisons between positional categories of senior A rugby players. Br J Sports Med 1996;30:53-6.

19. Nicholas CW. Anthropometric and physiological characteristics of rugby union football players. Sports Med 1997;23:375-96.

20. Quarrie KL, Wilson BD. Force production in the rugby union scrum. J Sports Sci 2000;18:237-46.

21. Preatoni E, Stokes KA, England ME, et al. The influence of playing level on the biomechanical demands experienced by rugby union forwards during machine scrummaging. Scand J Med Sci Sports 2013;23:e178-e184.

22. Preatoni E, Stokes KA, England ME, et al. Engagement techniques and playing level impact the biomechanical demands on rugby forwards during machine-based scrummaging. Br J Sports Med 2015;49:520-8.

23. Preatoni E, Cazzola D, Stokes KA, et al. Pre-binding prior to full engagement improves loading conditions for front-row players in contested Rugby Union scrums. Scand J Med Sci Sports 2016;26:1398-407.

24. Cazzola D, Preatoni E, Stokes KA, et al. A modified prebind engagement process reduces biomechanical loading on front row players during scrummaging: a cross-sectional study of 11 elite teams. Br J Sports Med 2015;49:541-6.

25. Cazzola D, Stone B, Holsgrove TP, et al. Spinal muscle activity in simulated rugby union scrummaging is affected by different engagement conditions. Scand J Med Sci Sports 2016;26:432-40.

26. Cazzola D, Preatoni E, Stokes KA, et al. A modified prebind engagement process reduces biomechanical loading on front row players during scrummaging: a cross-sectional study of 11 elite teams. Br J Sports Med 2015;49:541-6.

27. Aruin AS. Enhancing anticipatory postural adjustments: a novel approach to balance rehabilitation. J Nov Physiother 2016;6.

28. Hrysomallis C, Strength NM. Neck muscular strength, training, performance and sport injury risk: a review. Sports Med 2016;46:1111-24.

29. Marsden CD, Rothwell JC, Traub MM. Changes in perceived heaviness in man after thumb anaesthesia are associated with corresponding changes in the degree of muscle activation [proceedings]. J Physiol 1978;280:66P-7. 
30. Cordo PJ, Nashner LM. Properties of postural adjustments associated with rapid arm movements. J Neurophysiol 1982;47:287-302.

31. Bouisset S, Zattara M. Biomechanical study of the programming of anticipatory postural adjustments associated with voluntary movement. J Biomech 1987;20:735-42.

32. Kanekar N, Aruin AS. Improvement of anticipatory postural adjustments for balance control: effect of a single training session. J Electromyogr Kinesiol 2015;25:400-5.

33. Aruin AS, Shiratori T, Latash ML. The role of action in postural preparation for loading and unloading in standing subjects. Exp Brain Res 2001;138:458-66.

34. Massion J. Movement, posture and equilibrium: interaction and coordination. Prog Neurobiol 1992;38:35-56.

35. Shiratori T, Latash ML. Anticipatory postural adjustments during load catching by standing subjects. Clin Neurophysiol 2001;112:1250-65.

36. Santos MJ, Aruin AS. Role of lateral muscles and body orientation in feedforward postural control. Exp Brain Res 2008;184:547-59.

37. Santos MJ, Aruin AS. Effects of lateral perturbations and changing stance conditions on anticipatory postural adjustment.

$J$ Electromyogr Kinesiol 2009;19:532-41.

38. Aruin AS, Forrest WR, Latash ML. Anticipatory postural adjustments in conditions of postural instability. Electroencephalogr Clin Neurophysiol 1998;109:350-9.

39. Gantchev GN, Dimitrova DM. Anticipatory postural adjustments associated with arm movements during balancing on unstable support surface. Int J Psychophysiol 1996;22:117-22.

40. Gurfinkel VS, Levik YS, Kazennikov OV, et al. Locomotor-like movements evoked by leg muscle vibration in humans. Eur $J$ Neurosci 1998;10:1608-12.

41. van der Fits IB, Klip AW, van Eykern LA, et al. Postural adjustments accompanying fast pointing movements in standing, sitting and lying adults. Exp Brain Res 1998;120:202-16.

42. Danna-Dos-Santos A, Degani AM, Latash ML. Anticipatory control of head posture. Clin Neurophysiol 2007;118:1802-14.

43. Park RJ, Tsao H, Cresswell AG, et al. Anticipatory postural activity of the deep trunk muscles differs between anatomical regions based on their mechanical advantage. Neuroscience 2014;261:161-72.

44. Stamenkovic A, Stapley PJ. Trunk muscles contribute as functional groups to directionality of reaching during stance. Exp Brain Res 2016;234:1119-32.

45. Yakovenko S, Drew T. A motor cortical contribution to the anticipatory postural adjustments that precede reaching in the cat. J Neurophysiol 2009;102:853-74.

46. Richard A, Van Hamme A, Drevelle X, et al. Contribution of the supplementary motor area and the cerebellum to the anticipatory postural adjustments and execution phases of human gait initiation. Neuroscience 2017:358:181-9.

47. Massé-Alarie H, Neige $\mathrm{C}$, Bouyer LJ, et al. Modulation of corticospinal excitability of trunk muscles in preparation of rapid arm movement. Neuroscience 2018;369:231-41.

48. Holstege G. The anatomy of the central control of posture: consistency and plasticity. Neurosci Biobehav Rev 1998;22:485-93.

49. Schepens B, Drew T. Descending signals from the pontomedullary reticular formation are bilateral, asymmetric, and gated during reaching movements in the cat. J Neurophysiol 2006;96:2229-52.

50. Schepens B, Stapley P, Drew T. Neurons in the pontomedullary reticular formation signal posture and movement both as an integrated behavior and independently. $J$ Neurophysiol 2008;100:2235-53.

51. Lin CC, Creath RA, Rogers MW. Variability of anticipatory postura adjustments during gait initiation in individuals with Parkinson disease. J Neurol Phys Ther 2016;40:40-6.
52. Moseley GL, Hodges PW, Paul W. Reduced variability of postural strategy prevents normalization of motor changes induced by back pain: a risk factor for chronic trouble? Behav Neurosci 2006:120:474-6.

53. Jacobs JV, Henry SM, Nagle KJ. People with chronic low back pain exhibit decreased variability in the timing of their anticipatory postural adjustments. Behav Neurosci 2009;123:455-8.

54. Lee YJ, Aruin AS. Three components of postural control associated with pushing in symmetrical and asymmetrical stance. Exp Brain Res 2013;228:341-51.

55. Lee YJ, Aruin AS. Isolated and combined effects of asymmetric stance and pushing movement on the anticipatory and compensatory postural control. Clin Neurophysiol 2014;125:768-76

56. Mezaour M, Yiou E, Le Bozec S. Does symmetrical upper limb task involve symmetrical postural adjustments? Gait Posture 2009;30:239-44.

57. Bleuse S, Cassim F, Blatt JL, et al. Effect of age on anticipatory postural adjustments in unilateral arm movement. Gait Posture 2006:24:203-10.

58. Fujiwara K, Tomita $\mathrm{H}$, Maeda $\mathrm{K}$, et al. Effects of neck flexion on contingent negative variation and anticipatory postural control during arm movement while standing. $J$ Electromyogr Kinesiol 2009;19:113-21.

59. McCombe Waller S, Forrester L, Villagra F, et al. Intracortical inhibition and facilitation with unilateral dominant, unilateral nondominant and bilateral movement tasks in left- and right-handed adults. J Neurol Sci 2008;269:96-104.

60. Larivière $\mathrm{C}$, Butler $\mathrm{H}$, Sullivan $\mathrm{MJ}$, et al. An exploratory study on the effect of pain interference and attentional interference on neuromuscular responses during rapid arm flexion movements. Clin J Pain 2013:29

61. Bussey MD, Castro MP, Aldabe D, et al. Sex differences in anticipatory postural adjustments during rapid single leg lift. Hum Mov Sci 2018:57:417-25.

62. Cau N, Cimolin V, Galli M, et al. Center of pressure displacements during gait initiation in individuals with obesity. J Neuroeng Rehabil 2014;11:82

63. Calatayud J, Borreani S, Colado JC, et al. Exercise and ankle sprain injuries: a comprehensive review. Phys Sportsmed 2014;42:88-93.

64. Yiou E, Deroche T, Do MC, et al. Influence of fear of falling on anticipatory postural control of medio-lateral stability during rapid leg flexion. Eur J Appl Physiol 2011;111:611-20.

65. Uemura K, Yamada M, Nagai K, et al. Older adults at high risk of falling need more time for anticipatory postural adjustment in the precrossing phase of obstacle negotiation. J Gerontol A Biol Sci Med Sci 2011;66:904-9.

66. Mornieux G, Gehring D, Fürst P, et al. Anticipatory postural adjustments during cutting manoeuvres in football and their consequences for knee injury risk. J Sports Sci 2014;32:13:1255-62.

67. Hwang JA, Bae SH, Do Kim G, Kim GD, et al. The effects of sensorimotor training on anticipatory postural adjustment of the trunk in chronic low back pain patients. J Phys Ther Sci 2013;25:1189-92.

68. Brooks C, Kennedy S, Marshall PW. Specific trunk and general exercise elicit similar changes in anticipatory postural adjustments in patients with chronic low back pain: a randomized controlled trial. Spine 2012;37:E1543-50.

69. Kanekar N, Aruin AS. Improvement of anticipatory postural adjustments for balance control: effect of a single training session. $J$ Electromyogr Kinesiol 2015;25:400-5. 